\title{
Resistance to Fracture of Zirconia Abutments with Different Angulations: Impact of Implant Platform Diameter
}

\author{
Samah Saker ${ }^{1} \quad$ Walid AL-Zordk ${ }^{1} \quad$ Mutlu Özcan² \\ ${ }^{1}$ Fixed Prosthodontics Department, Faculty of Dentistry, Mansoura \\ University, Mansoura, Egypt \\ 2University of Zurich, Center of Dental Medicine, Division of \\ Dental Biomaterials, Clinic for Reconstructive Dentistry, Zurich, \\ Switzerland \\ Eur J Dent:2020;14:517-524
}

\begin{abstract}
Address for correspondence Samah Saker, PhD, Fixed Prosthodontics Department, Faculty of Dentistry, Mansoura University, 35516 El Gomhoria Street, Mansoura 35516, Egypt (e-mail: samah_saker@hotmail.com).
\end{abstract}

\begin{abstract}
Objective The aim of this study was to assess the impact of implant platform diameters on ultimate force to failure of zirconia abutments with different angulation.

Materials and Methods Forty-two zirconia abutments with either 0 degree (ST) or 15-degree (AN) angulation were assembled on tapered internal connection titanium implants (Direct's Legacy; $13 \mathrm{~mm}$ Implant Direct, LLC, Las Vegas, United States) with a platform diameter of $\varnothing 3.0, \varnothing 3.5$, and $\varnothing 4.5 \mathrm{~mm}$ (14 per group). Zirconia crowns (Ceramill Zolid; Amann Girrbach $\mathrm{GmbH}$ ) were fabricated and cemented using self-adhesive resin cement (MaxCem Elite, Kerr). The specimens were thermomechanically loaded $\left(\mathrm{TCML}=6,000\right.$ cycles of 5 to $50^{\circ} \mathrm{C}$ for 2 minutes/cycle followed by cyclic loading 600,000 cycles) followed by static loading until fracture. The data of load (N) at which fracture occurred were statistically analyzed by using Kruskal-Wallis analysis of variance and Mann-Whitney $U$ tests at $5 \%$ significance level.

Results Higher load to fracture was reported for zirconia crowns in straight abutments groups and a platform of $4.5,3.5$, and $3 \mathrm{~mm}$ diameter was $438.2 \pm 85.4,345.5 \pm 71.3$,

Keywords

- zirconia abutment

- fracture resistance

- abutment angulations

- implant diameters and $331.1 \pm 59.1 \mathrm{~N}$, respectively. However, the groups restored with zirconia crowns in angulated abutments groups and a platform of $4.5,3.5$, or $3 \mathrm{~mm}$ diameter showed a fracture load of $411.4 \pm 49.8,354.2 \pm 52.5$, and $302.8 \pm 52.5 \mathrm{~N}$, respectively.

Conclusion Straight and angulated zirconia abutments presented similar load to fracture on 3 and $3.5 \mathrm{~mm}$ platform diameters yet being significantly less for $4.5 \mathrm{~mm}$ diameter.
\end{abstract}

\section{Introduction}

Using osseointegrated dental implants for restoring single missing teeth in esthetic region has become a treatment modality exhibiting high success rates. Color matching between natural teeth and the artificial replacement accompanied with soft tissue architecture maintenance around the implant restoration are important for restorations in esthetic area. ${ }^{1-5}$ To gain an optimal esthetics, it is important to harmonize the restoration with the surrounding soft tissue and adjacent natural teeth and to overcome the apparent discoloration showing through thin gingival tissues that result from metallic color of the titanium. ${ }^{6-8}$

In 1993, all-ceramic sintered alumina oxide abutments were introduced as an alternative to titanium abutments. ${ }^{9,10}$ Zirconium oxide restorative abutments were introduced and recorded for its white color, tissue tolerability, good mechanical properties, and enhancement of transmucosal portion design. ${ }^{6,11-14}$ 
No doubt that stock abutments have several merits, including expenses. Prefabricated components are simple in utilization and decrease the dental laboratory costs of fixed dental prostheses' fabrication. ${ }^{15}$ However, the main problem reported is the platform diameter and the associated emergence profile. ${ }^{9}$

As a consequence of bone remodeling following tooth loss, the implant installation typically goes after the center of the remaining bone volume; the implant axis would pierce through the buccal side of the prospective crown. For fear of this, restorative foundations with angulation offsets are existing. However, many studies reported higher stresses at crestal bone area around the implant when an identical vertical load was applied to preangled abutments compared with straight abutments. ${ }^{16-19}$

The implant-abutment junction mostly has a prosthetic stand for abutment seating. This platform offers physical resistance to axial occlusal burdens. When angled or lateral loads cannot be knocked out, the magnitude of the force applied should be reduced or extra surface area of support is advised to decrease the hazard of biomechanical perplexity. ${ }^{20-22}$

The magnitude of force on an abutment retaining screw decreases with a large diameter implant. Diameter has been shown to play a role in the performance of zirconia abutment. ${ }^{23}$ In an investigation performed by Ellakwa et al, ${ }^{24}$ they studied the load fatigue performance of three different diameters of zirconia abutments and they reported that, the abutment diameter has an impact on load fatigue testing performance of zirconia abutments. To describe the diameter of dental implants, many terms had been used by many authors regardless the conformity and standardization. In this respect, a recent proposed classification based on the most frequently reported terms in reviewed articles, these terms were extra-narrow ( $<3.0 \mathrm{~mm}$ ), narrow (3.0 to $<3.75 \mathrm{~mm}$ ), standard ( 3.75 to $<5 \mathrm{~mm}$ ), and wide $(5.0 \mathrm{~mm}$ or more), because these were the most frequently used terms. ${ }^{23}$

Previous studies evaluated single implant-supported fixed dental prostheses with straight zirconia abutments based on the impact of some variables such as abutment preparation and wall thickness on resistance to fracture of the zirconia abutments. ${ }^{24-33}$ However, in vitro testing and characterization of the mechanical performance of angulated zirconia abutments with different diameters are seldom found in literature. Therefore, the purpose of the present study was to test the fracture behavior of both straight and angulated zirconia abutment supporting anterior single crown. Another purpose of the study was to investigate the impact of different implant diameters on the load-to fracture of both straight and angulated zirconia abutments supporting anterior single crown.

\section{Materials and Methods}

Two-piece implant system (Legacy; Implant Direct LLC, United States) with a length of $13 \mathrm{~mm}$ and a platform diameter of 3, 3.5, or $4.5 \mathrm{~mm}$ were used. Prefabricated zirconia abutments (Legacy Contoured Zirconia Abutment; Implant
Direct LLC, United States) with either 0 or 15-degree angulations were selected. Forty-two zirconia abutments and implants were divided into six equal groups $(n=7)$. Group ST1, ST2, and ST3 simulated a clinical scenario from a prosthetic viewpoint, with a suitable implant position that allows the utilization of straight prosthetic abutment, with 3, 3.5 and 4.5 diameter, respectively. Groups AN1, AN2, and AN3 simulated a clinical scenario with a nonideal implant angulation that needs angulated prosthetic abutments, with $3,3.5$, and 4.5 diameter, respectively. All study groups simulated an anterior implant-supported crown scenario.

The right central incisor was removed from a maxillary typodont model (Kavo Dental). Then, the typodont model was used to mimic the clinical scenario of adequate clinical dimension of an anterior single crown. An impression, using PVS impression material (Coltene Rapid; Coltene, Altstatten, Switzerland), was recorded for the typodont model and two stone models were obtained after pouring with type IV dental stone. In groups 1, 2, and 3, the implant fixtures were installed axially in the center of the socket, whereas the implant fixtures were installed in the center of the socket with 15 degrees angulation in the labial direction for groups 4,5 , and 6 . The shoulder of all implants was positioned $3 \mathrm{~mm}$ below the mesial and distal papillae. The two casts were trimmed to create a block. Then, the impression was recorded for both blocks. Implants were positioned repeatedly into these impressions and mounted in acrylic resin (Pro Base Clear, Ivovlar Vivadent). Each zirconia abutment was engaged to its corresponding implant and the retaining abutment screw was tightened using a manual wrench and screwdriver to the desired torque of $35 \mathrm{Ncm}$ according to manufacturer's instructions. For fabrication of identical 42 monolithic zirconia crowns, each zirconia abutment was scanned (Ceramill Map 400; Amann Girrbach $\mathrm{GmbH}$ ) and restorations were virtually designed by a software (Ceramill Mind CAD; version 3.5.6.1408, Amann Girrbach $\mathrm{GmbH}$ ). The cement gab was set to $0.2 \mathrm{~mm}$. The restorations were milled from zirconia blocks (Ceramill Zolid, Amann Girrbach GmbH) using 5-axis milling unit (Ceramill Motion 2, Amann Girrbach $\mathrm{GmbH}$ ). The milling was performed with $1 \mathrm{~mm}$ diamond for gross milling and $0.4 \mathrm{~mm}$ for fine adjustment. All zirconia crowns were sintered in a sintering furnace (Ceramill Therm, Amann Girrbach $\mathrm{GmbH}$ ) at $1450^{\circ} \mathrm{C}$ according to manufacturer's instructions. Before cementing the crowns, the retaining screw access holes were blocked with gutta-percha. The sintered crowns were cemented to its corresponding abutments using self-adhesive resin cement (MaxCem Elite, Kerr). All procedures were performed following the instructions of the manufacturer.

The specimens were aged by mean of thermocycling (6,000 cycles between 5 and $55^{\circ} \mathrm{C}$ for 60 seconds each and a dwell time of 12 second). A specially fabricated load cycling device was used with an upper rod with a $1.6 \mathrm{~mm}$ diameter that induced $50 \mathrm{~N}$ loads for 600,000 times with a frequency of 2 cycle per second at an angle of 30 degrees and with contact on the palatal surface $2 \mathrm{~mm}$ below the incisal edge of the crown. 
After the completion of loading cycles, all specimens were visually inspected for incipient fracture and screw loosening followed by low power magnification (Carl Zeiss, Jena, Germany). Signs of crack or fracture of the ceramic as well as screw loosening were considered as failure. Then, all survived specimens were quasi-static loaded using a universal testing machine (Lloyd, Lloyd Instruments Ltd, UK). Each specimen was secured to the lower compartment of the universal testing machine with the long axis of the crown at an angle of 30 degrees with load direction. A $0.5 \mathrm{~mm}$ tin foil sheet was positioned in between loading tip and palatal surface of the zirconia crown to ensure even force distribution during loading. Static loading was performed at a crosshead speed of $0.5 \mathrm{~mm} / \mathrm{min}$ with the force transferred to the palatal surface $2 \mathrm{~mm}$ bellow the incisal edge of the crown. The crosshead speed motion was stopped after the load started to decrease because of fracture or plastic deformation and the maximum load was recorded as the failure load.

All tested specimens were evaluated for incipient fractures to assess the failure mode that was categorized according to possible locations of the fractures. Representative fractured specimens from each group were sputtered and examined with a scanning electron microscope.

Statistical analysis was performed using Statistical Package for the Social Sciences software (version 17.0; SPSS Inc., Chicago, Illinois, United States). Due to the chosen sample size, statistical analysis of the fracture strength values $(\mathrm{N})$ of all specimens was performed using nonparametric Kruskal-Wallis analysis of variance and Mann-Whitney $U$ test. The significance level was set at $p$-values less than 0.05 .

\section{Results}

No fracture was observed in all tested groups following thermal cycling and mechanical loading for 600,000 cycles. Load to fracture values $(\mathrm{N})$ for all tested groups was presented in - Table 1. Higher fracture loads were reported for zirconia crowns in straight abutments groups and a platform of 4.5 , 3.5 , and $3 \mathrm{~mm}$ diameter was $438.2 \pm 85.4,345.5 \pm 71.3$, and $331.1 \pm 59.1 \mathrm{~N}$, respectively. While the groups restored with zirconia crowns in angulated abutments groups and a platform of $4.5,3.5$, or $3 \mathrm{~mm}$ diameter showed a fracture load of $411.4 \pm 49.8,354.2 \pm 52.5$ and $302.8 \pm 52.5 \mathrm{~N}$, respectively.
Irrespective to the platform diameter used, there is no significant difference between the load bearing capability of zirconia crowns in test groups with both 0 - and 15-degrees abutment angulations ( $p=0.07$ ).

Kruskal-Wallis analysis of variance revealed a significant difference between the load to fracture values of zirconia crowns in groups ST1and ST3 and AN1 and AN3 where $p=0.001$.

The failure mode reported for all tested specimens was ceramic fracture at or slightly above the implant shoulder level and the fractured parts always remained inside the internal connection part of the implants (-Figs. 1-7).

\section{Discussion}

Dental implants in the anterior area of the mouth are not installed in optimum axial positions depending on the ridge thickness and the amount of bone and space available. ${ }^{18}$ To compensate for this shift and provide compatibility between the position of the implant and the proposed restoration, angulated abutments are commonly used.

Angulated abutments are available with angulations of 15 to 30 degrees. The wall thickness on the side of an angulated abutment decreases in direct relation to the degree of angulation. Therefore, the risk of fracture is raised from both an increased shear component of force and decrease in wall component strength. The clinical use of angulated abutments should be limited only to correct the path of withdrawal of the restoration or enhance the cosmetic appearance. When the angulated abutment is loaded along its long axis, a significant moment load is transmitted to entire installed implant system. Most implant fixtures installed with angle more than 12 degrees to the horizontal plane need an angulated abutment. Thulasidas et $\mathrm{al}^{22}$ investigated the effect of custom milled zirconia abutments with different angulations and they reported that tilting the implant apex toward the lingual significantly minimized the fracture strength of custom milled zirconia abutment compared with straight zirconia abutment.

In the current study, the resistance to fracture values in groups restored using a platform diameter of $4.7 \mathrm{~mm}$ is higher than those with $3.2 \mathrm{~mm}$ diameter irrespective to abutment angulation used. A study performed by Mish $^{34}$ reported that, the ability of an implant to resist fracture or deformation

Table 1 Mean force $(\mathrm{N})$ at fracture in groups with either straight or angulated zirconia abutments with different platform diameter

\begin{tabular}{|l|l|l|l|l|}
\hline Groups & Platform diameter $(\mathbf{m m})$ & $\boldsymbol{n}$ & Mean & SD \\
\hline Straight abutment & 3 & 7 & $331.1^{\mathrm{a}}$ & 59.1 \\
\cline { 2 - 5 } & 3.5 & 7 & $345.5^{\mathrm{a}}$ & 71.3 \\
\cline { 2 - 5 } & 4.5 & 7 & $438.2^{\mathrm{b}}$ & 85.4 \\
\hline \multirow{3}{*}{ Angulated abutment } & 3 & 7 & $302.8^{\mathrm{a}}$ & 52.5 \\
\cline { 2 - 5 } & 3.5 & 7 & $354.2^{\text {a }}$ & $411.4^{\mathrm{b}}$ \\
\cline { 2 - 5 } & 4.5 & 7 & 49.8 \\
\hline
\end{tabular}

Abbreviation: SD, standard deviation.

Note: Groups with same letter indicate no significant difference $(P<.05)$. 


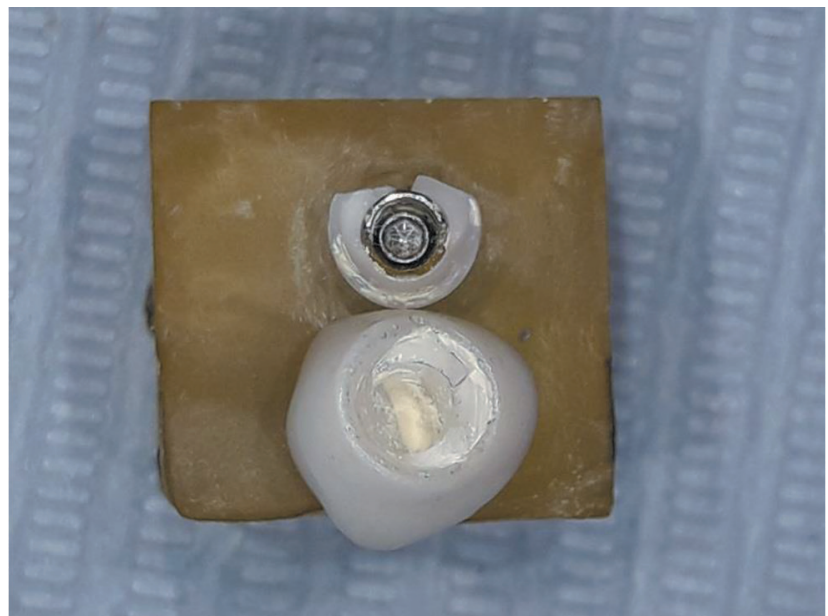

Fig. 1 Partially fractured zirconia abutment at the marginal level of the crown.

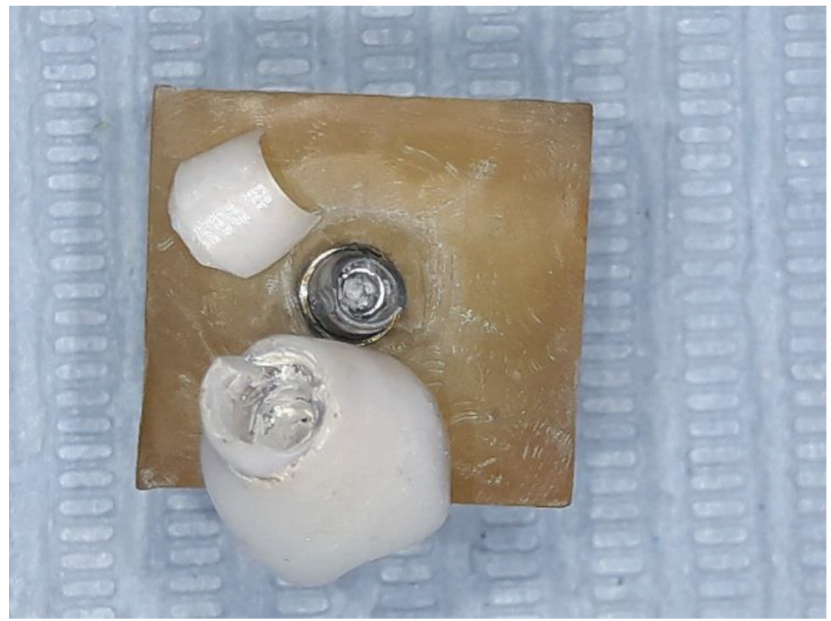

Fig. 2 Fracture of the zirconia abutment below the crown margin and around the titanium insert.

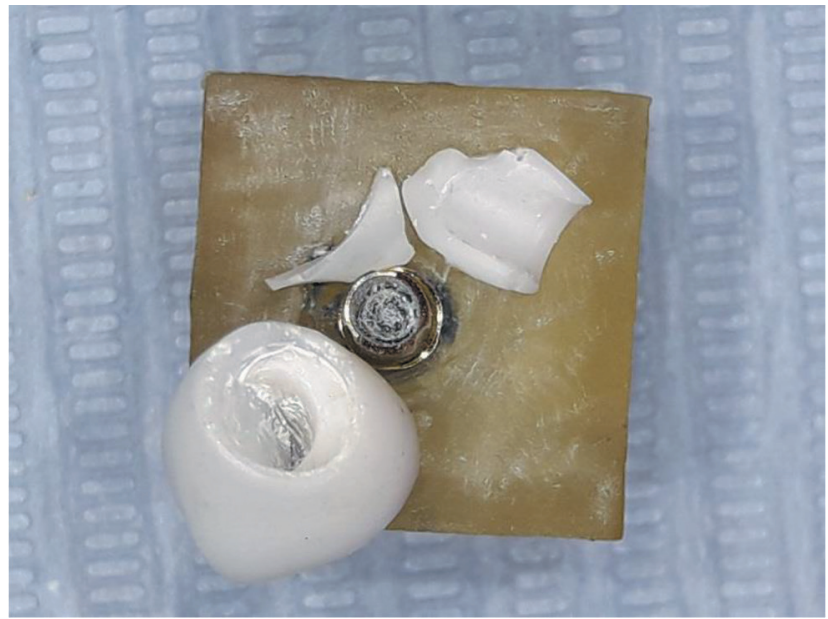

Fig. 3 Multiple fractures of the zirconia abutment above the platform. depends primarily on the size of a dental implant used. Twopiece implants are hollow devices, and the fracture resistance is inversely proportional to its radius. Minor changes in the diameter of the implant could end with significant changes in overall resistance against mechanical integrity. By increasing the diameter of the implant, its strength and endurance limit would also increase. The size of the implant plays a major role in improving its strength, but having sufficient bone volume in a patient's jaw for such placement is also a critical issue.

In our study, the test specimen assembly consisted of zirconia crown cemented to zirconia abutment with different angulation that was connected to implant fixture. Care was taken to exclude all influencing factors that could potentially appear from differences in the implant design crown used. Shape, dimensions, and material of the crown were standardized by machining technology. Monolithic zirconia crowns were selected for the in vitro test setup for an anterior full coverage restoration to be consistent with clinical practice. Monolithic zirconia restorations with single-layer design and favorable mechanical properties were introduced to avoid chipping. ${ }^{35}$ Although Nothdurft et a ${ }^{36}$ used full metal crowns for their test setup to avoid much cofactors, they were aware of the possible toughening influence of metallic crowns on the total value of the fracture load. In this study, the results collected showed that none of the monolithic zirconia crowns fractured through the load testing.

To rate implant-supported prosthesis reliable for clinical application, they have to overcome loads of 140 to $390 \mathrm{~N}$ during mastication. ${ }^{37}$ In our study, load to fracture values for all tested specimens was deemed to be within or over the borders of the utmost physiological forces in the upper anterior area of the mouth. ${ }^{38,39}$

Almost all released publications on zirconia implant abutments studied anterior single replacements that reported load to fracture values between 429 and $793 \mathrm{~N}$ with load angles ranging from 30 to 60 degrees. ${ }^{40-42}$ Also, it is of value to take into consideration the forces that can be anticipated during function in the patient's mouth. The reported weighted bite forces in healthy men for maxillary incisors are 150 and $140 \mathrm{~N}$ with higher bite forces reported with functional disorder such as bruxism. ${ }^{43,44}$ For all groups in our study, the measured fracture loads exceed the above-mentioned forces.

In this study, thermomechanically loaded (TCML) artificial aging of the specimens was performed with the same parameters used in literature. ${ }^{45,46}$

The fracture of the abutments was lying at the neck region of the abutments and the most typical fracture pattern was ceramic fracture at or a little up the implant shoulder plane and the shattered parts always existed within the internal connection region of the implants.

This observation confirms findings of other studies. The fracture of zirconia abutments typically taken place at cervical aspect of the abutment, nearby the abutment retaining screw 


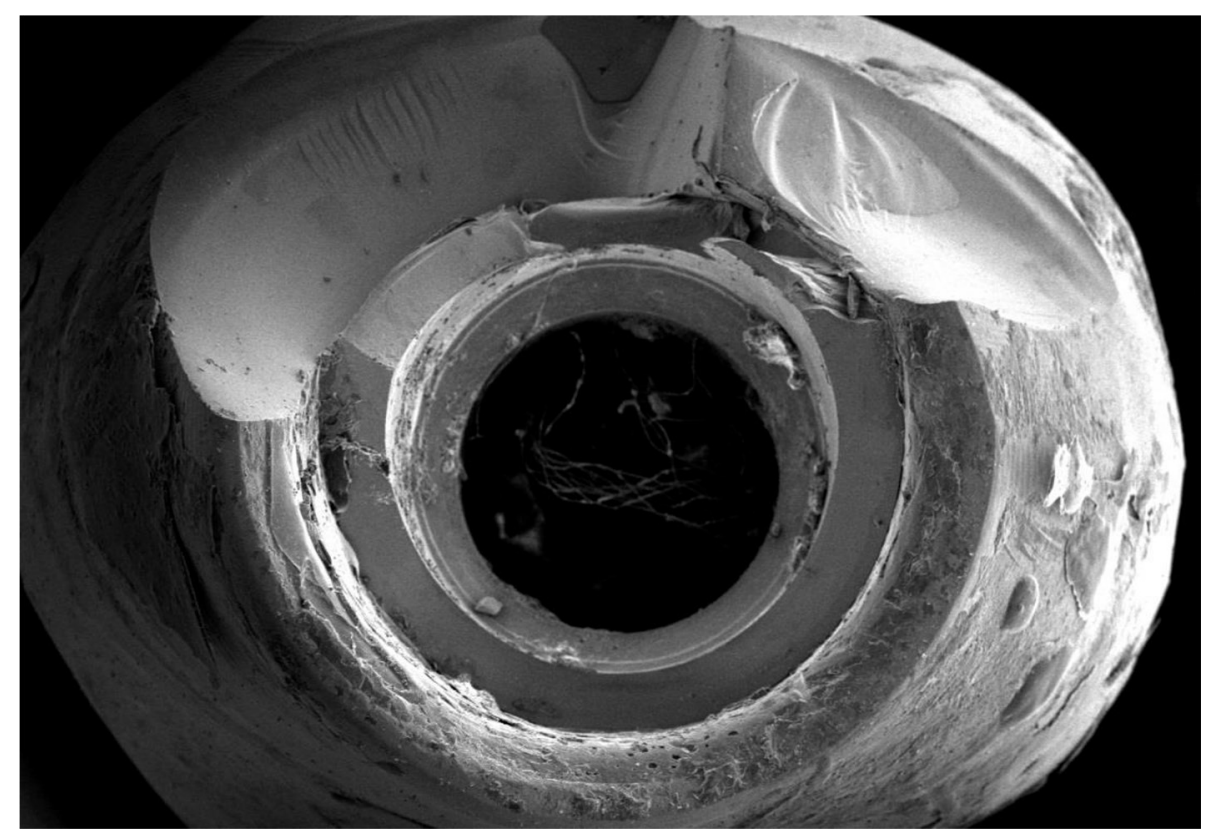

Fig. 4 Scanning electron microscopic image of partially fractured zirconia abutment crown.

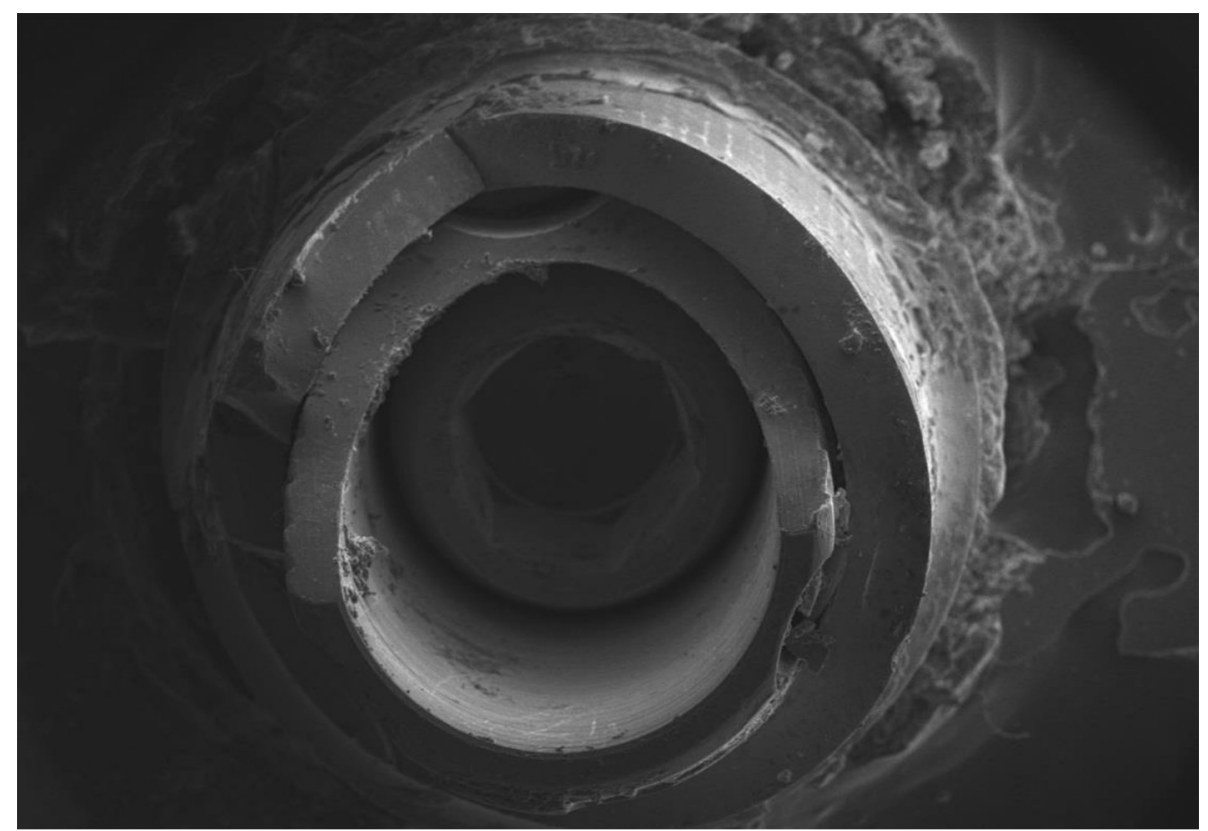

Fig. 5 Scanning electron microscopic overview of fractured angulated zirconia abutment with fracture starting from the lingual side.

and implant platform. This region of the abutment has been revealed to have the greatest torque and stress concentration due to levering consequences. ${ }^{36,40}$

The mean fracture resistance values of zirconia abutment recorded in our study are within the range of values (184-793 N) published in comparable published investigations. ${ }^{36,41,45,48}$ These variations may arise from differences in the study setups and implant-abutment connections. Sailer et $\mathrm{a}^{48}$ showed that the sort of implant-abutment junction significantly influenced the strength of zirconia abutments. Titanium base of the zirconia abutment may decrease fracture risk. ${ }^{49}$ Alsahhaf et al ${ }^{50}$ demonstrated that the titanium base in the two-piece zirconia abutment acts as a replace for the weakest portion of the zirconia abutment. Consequently, the titanium base can strengthen the fracture strength of a zirconia abutment and can therefore be recommended as an esthetic alternative for implant reconstruction in the anterior region.

Nguyen et al studied the load fatigue performance of different implant-zirconia abutment structures and concluded that fatigue testing execution of zirconia abutment is determined by the abutment diameter. ${ }^{27}$

In our study, there was a difference in the maximum static loads and endurance limits between the straight and angulated abutments. The reason for the superior endurance limit with angulated abutments may be the design itself. Since the 


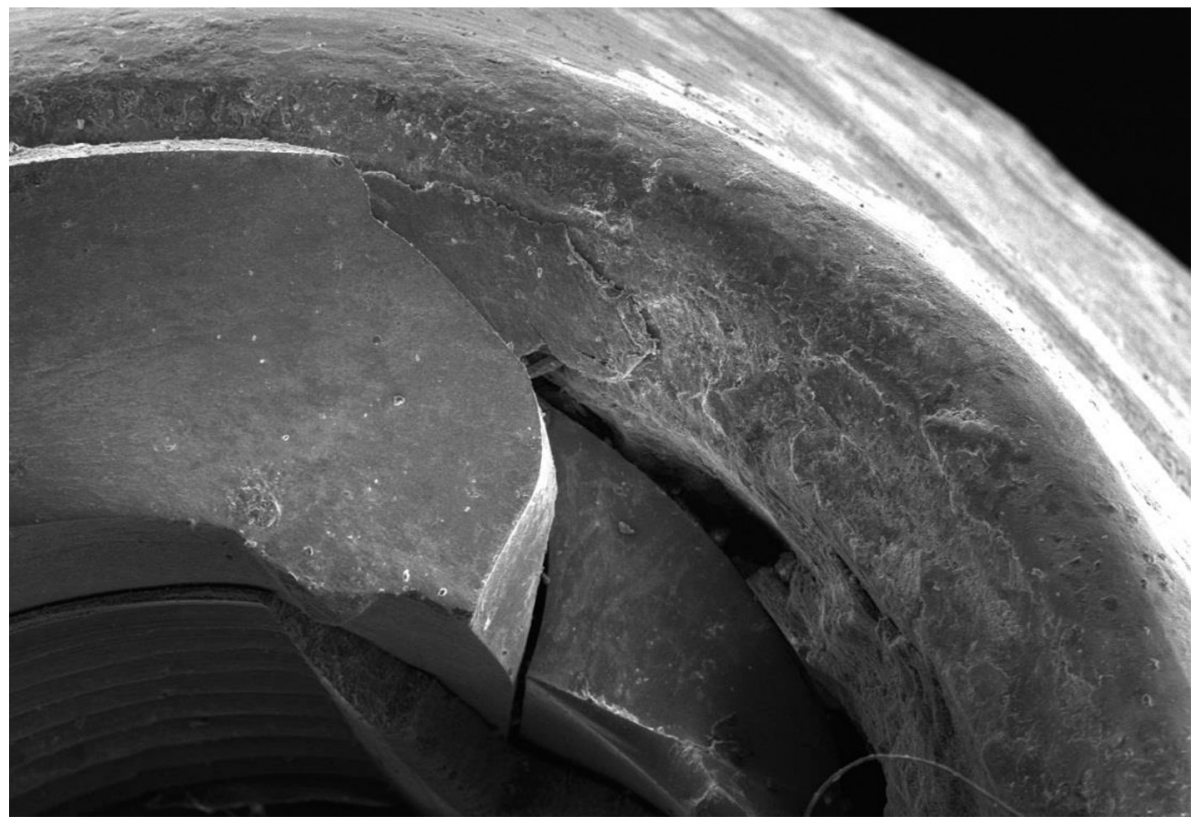

Fig. 6 Representative scanning electron microscopic image of the fracture area in the region of platform.

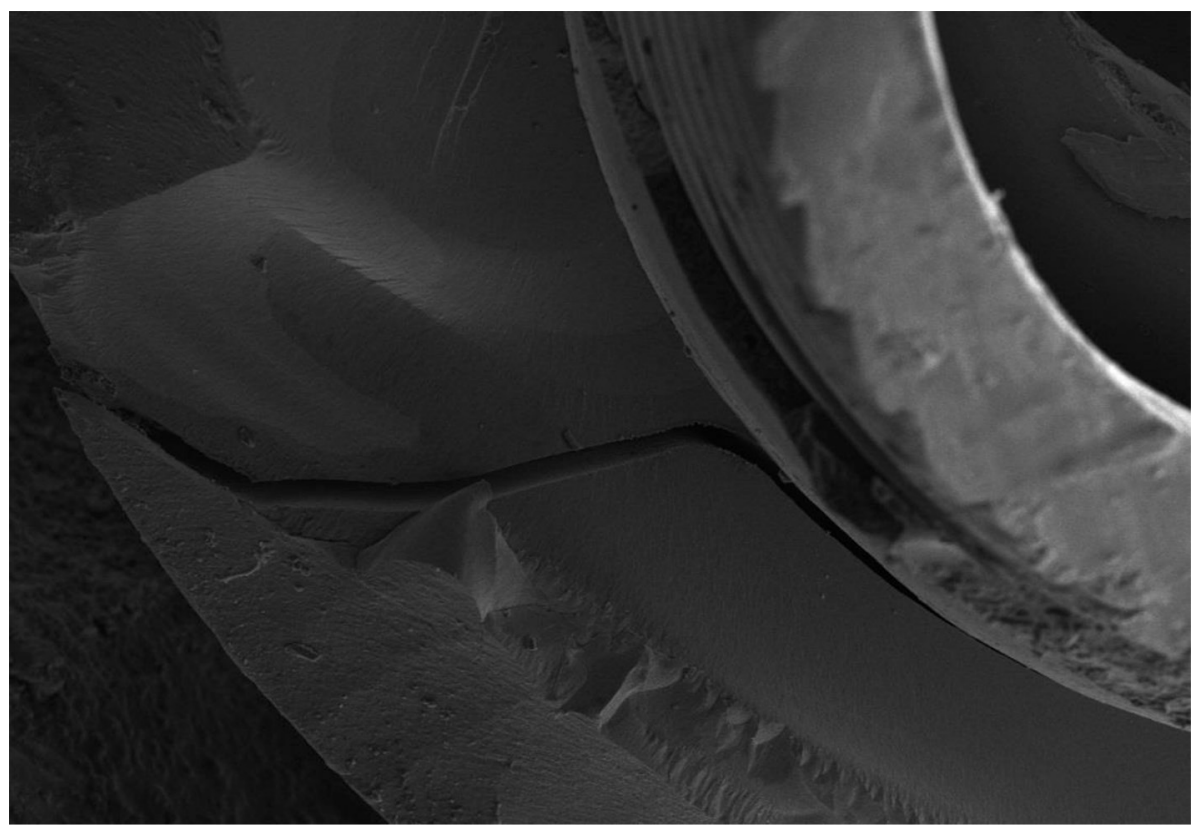

Fig. 7 Scanning electron microscopic image of fractured zirconia abutment with fractured origin determined by the hackle lines reveal crack propagation direction.

moment arm is the horizontal distance between the center of the restoration and the center of the fixture at the level of the specimen fixation, then the system with the straight abutment suffers from more bending than with the angulate abutment. Also, the straight abutment has a tapered cylindrical shape, while the angulated abutment terminates with a crescent apex. As mentioned in the results, no screw or implant body fractures are seen in the present study.

\section{Conclusion}

Straight and angulated zirconia abutments presented similar load to fracture on 3 and $3.5 \mathrm{~mm}$ platform diameters yet being significantly less for $4.5 \mathrm{~mm}$ diameter.

\section{Conflict of Interest}

None declared. 


\section{References}

1 Kniha K, Modabber A, Kniha H, Möhlhenrich SC, Hölzle F, Milz S. Dimensions of hard and soft tissue around adjacent, compared with single-tooth, zirconia implants. Br J Oral Maxillofac Surg 2018;56(1):43-47

2 Gao E, Hei WH, Park JC, et al. Bone-level implants placed in the anterior maxilla: an open-label, single-arm observational study. J Periodontal Implant Sci 2017;47(5):312-327

3 den Hartog L, Meijer HJA, Vissink A, Raghoebar GM. Anterior single implants with different neck designs: 5 year results of a randomized clinical trial. Clin Implant Dent Relat Res 2017;19(4):717-724

4 Arunyanak SP, Pollini A, Ntounis A, Morton D. Clinician assessments and patient perspectives of single-tooth implant restorations in the esthetic zone of the maxilla: a systematic review. J Prosthet Dent 2017;118(1):10-17

5 Spies BC, Witkowski S, Vach K, Kohal RJ. Clinical and patient-reported outcomes of zirconia-based implant fixed dental prostheses: results of a prospective case series 5 years after implant placement. Clin Oral Implants Res 2018;29(1):91-99

6 Andersson B, Taylor A, Lang BR, et al. Alumina ceramic implant abutments used for single-tooth replacement: a prospective 1- to 3-year multicenter study. Int J Prosthodont 2001;14(5):432-438

7 Elsayed A, Wille S, Al-Akhali M, Kern M. Effect of fatigue loading on the fracture strength and failure mode of lithium disilicate and zirconia implant abutments. Clin Oral Implants Res 2018;29(1):20-27

8 Yu SJ, Shan WL, Liu YX, Huang XY, Zhu GX. Effects of four different crown materials on the peri-implant clinical parameters and composition of peri-implant crevicular fluid. J Oral Implantol 2017;43(5):337-344

9 Prestipino V, Ingber A. Esthetic high-strength implant abutments. Part I. J Esthet Dent 1993;5(1):29-36

10 Prestipino V, Ingber A. Esthetic high-strength implant abutments. Part II. J Esthet Dent 1993;5(2):63-68

11 Piconi C, Maccauro G. Zirconia as a ceramic biomaterial. Biomaterials 1999;20(1):1-25

12 Glauser R, Sailer I, Wohlwend A, Studer S, Schibli M, Schärer P. Experimental zirconia abutments for implant-supported single-tooth restorations in esthetically demanding regions: 4 -year results of a prospective clinical study. Int J Prosthodont 2004;17(3):285-290

13 Ichikawa Y, Akagawa Y, Nikai H, Tsuru H. Tissue compatibility and stability of a new zirconia ceramic in vivo. J Prosthet Dent 1992;68(2):322-326

14 Heydecke G, Sierraalta M, Razzoog ME. Evolution and use of aluminum oxide single-tooth implant abutments: a short review and presentation of two cases. Int J Prosthodont 2002;15(5):488-493

15 Watkin A, Kerstein RB. Improving darkened anterior peri-implant tissue color with zirconia custom implant abutments. Compend Contin Educ Dent 2008;29(4):238-240, 242

16 Sethi A, Kaus T, Sochor P, Axmann-Krcmar D, Chanavaz M. Evolution of the concept of angulated abutments in implant dentistry: 14-year clinical data. Implant Dent 2002;11(1):41-51

17 Nothdurft FP, Doppler KE, Erdelt KJ, Knauber AW, Pospiech PR. Influence of artificial aging on the load-bearing capability of straight or angulated zirconia abutments in implant/ tooth-supported fixed partial dentures. Int J Oral Maxillofac Implants 2010;25(5):991-998

18 Sethi A, Kaus T, Sochor P. The use of angulated abutments in implant dentistry: five-year clinical results of an ongoing prospective study. Int J Oral Maxillofac Implants 2000;15(6):801-810
19 Boggan RS, Strong JT, Misch CE, Bidez MW. Influence of hex geometry and prosthetic table width on static and fatigue strength of dental implants. J Prosthet Dent 1999;82(4):436-440

20 Duyck J, Van Oosterwyck H, Vander Sloten J, De Cooman M, Puers R, Naert I. Magnitude and distribution of occlusal forces on oral implants supporting fixed prostheses: an in vivo study. Clin Oral Implants Res 2000;11(5):465-475

21 Ha CY, Lim YJ, Kim MJ, Choi JH. The influence of abutment angulation on screw loosening of implants in the anterior maxilla. Int J Oral Maxillofac Implants 2011;26(1):45-55

22 Thulasidas S, Givan DA, Lemons JE, O'Neal SJ, Ramp LC, Liu PR. Influence of implant angulation on the fracture resistance of zirconia abutments. J Prosthodont 2015;24(2):127-135

23 Ellakwa A, Raj T, Deeb S, Ronaghi G, Martin FE, Klineberg I. Influence of implant abutment angulations on the fracture resistance of overlaying CAM-milled zirconia single crowns. Aust Dent J 2011;56(2):132-140

24 Al-Johany SS, Al Amri MD, Alsaeed S, Alalola B. Dental implant length and diameter: a proposed classification scheme. J Prosthodont 2017;26(3):252-260

25 Att W, Yajima ND, Wolkewitz M, Witkowski S, Strub JR. Influence of preparation and wall thickness on the resistance to fracture of zirconia implant abutments. Clin Implant Dent Relat Res 2012;14(Suppl 1) :e196-e203

26 Mitsias M, Koutayas SO, Wolfart S, Kern M. Influence of zirconia abutment preparation on the fracture strength of single implant lithium disilicate crowns after chewing simulation. Clin Oral Implants Res 2014;25(6):675-682

27 Nguyen HQ, Tan KB, Nicholls JI. Load fatigue performance of implant-ceramic abutment combinations. Int J Oral Maxillofac Implants 2009;24(4):636-646

28 Shabanpour R, Mousavi N, Ghodsi S, Alikhasi M. Comparative evaluation of fracture resistance and mode of failure of zirconia and titanium abutments with different diameters. J Contemp Dent Pract 2015;16(8):613-618

29 Stimmelmayr M, Sagerer S, Erdelt K, Beuer F. In vitro fatigue and fracture strength testing of one-piece zirconia implant abutments and zirconia implant abutments connected to titanium cores. Int J Oral Maxillofac Implants 2013;28(2):488-493

30 Kim JS, Raigrodski AJ, Flinn BD, Rubenstein JE, Chung KH, Mancl LA. In vitro assessment of three types of zirconia implant abutments under static load. J Prosthet Dent 2013;109(4):255-263

31 Basílio MdeA, Cardoso KV, Antonio SG, Rizkalla AS, Santos Junior GC, Arioli Filho JN. Effects of artificial aging conditions on yttria-stabilized zirconia implant abutments. J Prosthet Dent 2016;116(2):277-285

32 Joda T, Bürki A, Bethge S, Brägger U, Zysset P. Stiffness, strength, and failure modes of implant-supported monolithic lithium disilicate crowns: influence of titanium and zirconia abutments. Int J Oral Maxillofac Implants 2015;30(6):1272-1279

33 Sghaireen MG. Fracture resistance and mode of failure of ceramic versus titanium implant abutments and single implant-supported restorations. Clin Implant Dent Relat Res 2015;17(3):554-561

34 Mish C, Dental Implant Prosthetics. 2nd edition. Mosby Inc; Elsevier 2015 393-413

35 Guess PC, Schultheis S, Bonfante EA, Coelho PG, Ferencz JL, Silva NR. All-ceramic systems: laboratory and clinical performance. Dent Clin North Am 2011;55(2):333-352, ix

36 Nothdurft FP, Doppler KE, Erdelt KJ, Knauber AW, Pospiech PR. Fracture behavior of straight or angulated zirconia implant abutments supporting anterior single crowns. Clin Oral Investig 2011;15(2):157-163

37 Koc D, Dogan A, Bek B. Bite force and influential factors on bite force measurements: a literature review. Eur J Dent 2010;4(2):223-232 
38 Jörnéus L, Jemt T, Carlsson L. Loads and designs of screw joints for single crowns supported by osseointegrated implants. Int J Oral Maxillofac Implants 1992;7(3):353-359

39 Kiliaridis S, Kjellberg H, Wenneberg B, Engström C. The relationship between maximal bite force, bite force endurance, and facial morphology during growth. A cross-sectional study. Acta Odontol Scand 1993;51(5):323-331

40 Gehrke P, Dhom G, Brunner J, Wolf D, Degidi M, Piattelli A. Zirconium implant abutments: fracture strength and influence of cyclic loading on retaining-screw loosening. Quintessence Int 2006;37(1):19-26

41 Aramouni P, Zebouni E, Tashkandi E, Dib S, Salameh Z, Almas K. Fracture resistance and failure location of zirconium and metallic implant abutments. J Contemp Dent Pract 2008;9(7):41-48

42 Yildirim M, Fischer H, Marx R, Edelhoff D. In vivo fracture resistance of implant-supported all-ceramic restorations. J Prosthet Dent 2003;90(4):325-331

43 Ferrario VF, Sforza C, Serrao G, Dellavia C, Tartaglia GM. Single tooth bite forces in healthy young adults. J Oral Rehabil 2004;31(1):18-22

44 Nishigawa K, Bando E, Nakano M. Quantitative study of bite force during sleep associated bruxism. J Oral Rehabil 2001;28(5):485-491
45 Saker S, El-Shahat S, Ghazy M. Fracture resistance of straight and angulated zirconia implant abutments supporting anterior three-unit lithium disilicate fixed dental prostheses. Int J Oral Maxillofac Implants 2016;31(6):1240-1246

46 Heydecke G, Butz F, Hussein A, Strub JR. Fracture strength after dynamic loading of endodontically treated teeth restored with different post-and-core systems. J Prosthet Dent 2002;87(4):438-445

47 Kerstein RB, Radke J. A comparison of fabrication precision and mechanical reliability of 2 zirconia implant abutments. Int J Oral Maxillofac Implants 2008;23(6):1029-1036

48 Sailer I, Sailer T, Stawarczyk B, Jung RE, Hämmerle CH. In vitro study of the influence of the type of connection on the fracture load of zirconia abutments with internal and external implant-abutment connections. Int J Oral Maxillofac Implants 2009;24(5):850-858

49 Sailer I, Philipp A, Zembic A, Pjetursson BE, Hämmerle CH, Zwahlen M. A systematic review of the performance of ceramic and metal implant abutments supporting fixed implant reconstructions. Clin Oral Implants Res 2009;20(Suppl 4) :4-31

50 Alsahhaf A, Spies BC, Vach K, Kohal RJ. Fracture resistance of zirconia-based implant abutments after artificial long-term aging. J Mech Behav Biomed Mater 2017;66:224-232 